\title{
FAKTOR-FAKTOR YANG MEMPENGARUHI PARTISIPASI PRIA DALAM VASEKTOMI DI KECAMATAN SIDIKALANG TAHUN 2017
}

\author{
${ }^{1}$ Agustina R. Marbun, ${ }^{2}$ Wisnu Hidayat, ${ }^{3}$ Risnawati Sembiring \\ ${ }^{1,2,3}$ Program Studi Magister Ilmu Kesehatan Masyarakat Universitas Sari Mutiara Indonesia
}

Email : austin_rosel@yahoo.com

\begin{abstract}
ABSTRAK
Vasektomi adalah metode kontrasepsi bagi pria. Berdasarkan data yang diperoleh diketahui bahwa partisipasi pria dalam program keluarga berencana masih rendah. Penelitian ini merupakan penelitian observasional dengan rancangan case control study, yaitu membandingkan antara kelompok kasus dengan kelompok kontrol berdasarkan faktor predisposisi (pengetahuan, dan sikap), faktor pemungkin (ketersediaan layanan vasektomi dan keterjangkauan sarana kesehatan), serta faktor penguat (dukungan istri) yang memengaruhi penggunaan vasektomi di Kecamatan Sidikalang. Populasi dalam penelitian ini adalah semua suami yang menjadi akseptor vasektomi dengan jumlah 30 orang. Penelitian ini dilakukan bulan Maret sampai Juli 2017. Data diperoleh melalui wawancara dengan /J67responden dan dianalisis dengan uji regresi logistik berganda pada taraf kepercayaan 95\%. Hasil penelitian menunjukkan bahwa faktor predisposisi (pengetahuan, sikap), faktor pemungkin (ketersediaan pelayanan vasektomi dan keterjangkauan fasilitas kesehatan) dan faktor penguat (dukungan istri) berhubungan dengan partisipasi pria dalam vasektomi. Variabel yang memberikan pengaruh paling besar adalah pengetahuan dengan Odd Ratio 70,00. Disarankan kepada PLKB untuk memberikan penyuluhan dan konseling tentang vasektomi KB kepada masyarakat.
\end{abstract}

Kata kunci: Vasektomi, perencanaan keluarga, faktor yang mempengaruhi

\section{ABSTRACT}

Vasectomy is a method of contraception for men. Based on the data obtained, it is known that male participation in family planning program is still low. This study was an observational study with case control study design, ie comparing case group with control group based on predisposing factors (knowledge, attitude), enabling factors (availability of vasectomy service and affordability of health facilities), and strengthening factor (wife support) use of vasectomy in Sidikalang District. The population in this study is all the vases that become vasectomy acceptors with the number of 30 people. This study was conducted from March to July 2017. Data were obtained through interviews with respondents and analyzed by multiple logistic regression test at $95 \%$ confidence level. The results showed that predisposing factors (knowledge, attitudes), enabling factors (availability of vasectomy services and affordability of health facilities) and reinforcement factors (wife support) were associated with male participation in vasectomy. The variable that gives the most influence is knowledge with Odd Ratio 70,00. Suggested To PLKB to improve the ability in conveying information $K B$ to community.

Keywords: Vasectomy, Family Planning, Affecting Factors

\section{PENDAHULUAN}

Masalah yang dihadapi beberapa negara berkembang dewasa ini adalah mengurangi jumlah kemiskinan dengan menggunakan berbagai cara baik melalui peningkatkan infrastruktur ekonomi seperti membangun jalan, jembatan, pasar, serta sarana lain, maupun membangun derajat dan partisipasi masyarakat melalui peningkatan pendidikan maupun kesehatan. Namun demikian kendala utama yang dihadapi hampir semuanya sama, yang umumnya bersumber pada permasalahan kependudukan. Mulai dari masih tingginya angka kematian bayi dan ibu melahirkan, rendahnya kesadaran masyarakat tentang hak-hak reproduksi, serta masih cukup tingginya laju pertumbuhan penduduk (BKKBN, 2010). Kondisi kependudukan di Indonesia saat ini baik yang menyangkut jumlah, kualitas maupun persebarannya merupakan tantangan yang berat yang harus diatasi bagi tercapainya keberhasilan pembangunan bangsa Indonesia. Salah satu upaya yang telah dan perlu terus dilakukan 
oleh pemerintah bersama-sama dengan seluruh lapisan masyarakat adalah dengan pengendalian jumlah penduduk dan peningkatan kualitasnya melalui Program Keluarga Berencana (BKKBN, 2001).

Program Keluarga Berencana merupakan salah satu program prioritas dalam Sustainable Development Goals (SDGs), dimana program KB termuat dalam tujuan ketiga (Menjamin Kesehatan yang baik) dan tujuan kelima (menjamin kesetaraan gender serta memberdayakan seluruh wanita) melalui akses terhadap kesehatan reproduksi dan Badan Kependudukan Keluarga Berencana Nasioanal sebagai motor penggerak dalam melaksanakan Program Keluarga Berencana tersebut.

Selama ini masyarakat menganggap Program KB Nasional identik dengan kaum perempuan. Anggapan ini tidak berlebihan karena kenyataannya selama ini sasaran utama program KB sebagian besar adalah perempuan. Namun semua itu mulai berubah, kaum pria pun kini ikut menjadi akseptor KB. Dalam Rencana Pembangunan Jangka Menengah Nasional (RPJMN), salah satu indikator keberhasilan BKKBN adalah tercapainya kesertaaan KB pria sebesar $4,1 \%$ pada tahun 2017 (BKKBN, 2016).

Rendahnya partisipasi pria dalam KB dan kesehatan reproduksi pada dasarnya tidak terlepas dari operasional program KB yang selama ini dilaksanakan mengarah pada wanita sebagai sasaran. Demikian juga masalah penyediaan alat kontrasepsi yang hampir semuanya untuk wanita, sehingga pola pikir masyarakat mempunyai persepsi yang dominan yakni yang hamil dan melahirkan adalah wanita, maka wanitalah yang harus menggunakan alat kontrasepsi. Rendahnya partisipasi pria dalam KB juga disebabkan oleh pengetahuan suami mengenai KB secara umum relatif rendah, sebagaimana terungkap pada penelitian Suherni, dkk (1999) bahwa pria yang mengetahui secara lengkap tentang alat kontrasepsi wanita dan pria hanya $6.2 \%$.

Menurut Notoatmodjo (2010), yang mengutip teori Green, faktor yang memengaruhi pria dalam penggunaan kontrasepsi vasektomi dapat menggunakan pendekatan faktor perilaku pada kerangka kerja dari teori Green (1991) yaitu faktor predisposisi (predisposing factors) meliputi pendidikan, pekerjaan, pengetahuan, sikap, budaya), Faktor pemungkin (enabling factors) meliputi tersedianya pelayanan kesehatan, keterjangkauan, dan faktor penguat (reinforcing factors) meliputi perilaku tokoh masyarakat, tokoh agama, sikap dan perilaku para petugas termasuk petugas kesehatan).

Hasil studi pendahuluan di Dinas Pengendalian Penduduk dan Keluarga Berencana pada Maret 2017 diperoleh data akseptor KB pria di Kabupaten Dairi yaitu MOP sebanyak 198 orang (3,03\%) dan kondom 1208 orang (18,51\%). Dari 198 orang akseptor vasektomi, 30 orang diantaranya bertempat tinggal di Kecamatan Sidikalang. Data terakhir tahun 2014 kepesertaan vasektomi di Kecamatan Sidikalang menduduki peringkat pertama dibanding kcamatan lain. Akan tetapi, data per Desember 2016 Kecamatan Sidikalang menduduki peringkat ketiga setelah Kecamatan Sumbul dan Parbuluan. Angka ini cukup rendah karena Kecamatan Sidikalang memiliki jumlah PUS terbanyak di Kabupaten Dairi. Rendahnya jumlah partisipasi pria dalam vasektomi membuat peneliti tertarik untuk melakukan penelitian yang berjudul Faktor-Faktor Yang Memengaruhi Partisipasi Pria Dalam Vasektomi di Kecamatan Sidikalang Kabupaten Dairi Tahun 2017.

Penelitian ini bertujuan untuk mengetahui pengaruh faktor predisposisi (pengetahuan dan sikap), faktor pemungkin (ketersediaan pelayanan vasektomi dan keterjangkauan sarana kesehatan), serta faktor penguat (dukungan istri) terhadap partisipasi pria dalam vasektomi di Kecamatan Sidikalang Kabupaten Dairi Tahun 2017.

\section{METODE}

Jenis penelitian ini merupakan penelitian observasional dengan rancangan case control study (Setiadi, 2007) yaitu membandingkan antara kelompok kasus dengan kelompok kontrol berdasarkan faktor predisposisi (pengetahuan, dan sikap), faktor pemungkin (ketersediaan layanan vasektomi dan keterjangkauan sarana kesehatan), serta faktor penguat (dukungan istri) yang memengaruhi penggunaan vasektomi di Kecamatan Sidikalang. 
Populasi dalam penelitian ini adalah semua suami sebagai Pasangan Usia Subur pengguna vasektomi yang bertempat tinggal di wilayah kerja Kecamatan Sidikalang Kabupaten Dairi sebanyak 30 orang. Dalam penelitian ini sampel yang terpilih merupakan bagian dari populasi yang sudah memenuhi syarat untuk menjadi akseptor vasektomi yaitu berumur $>30$ tahun dan mempunyai anak $\geq 2$ orang. Sampel dalam penelitian dibedakan menjadi 2 yaitu kasus dan kontrol. Pada kelompok kasus jumlah sampel sebanyak 30 orang dengan teknik pengambilan sampel dengan sampling jenuh, yaitu bila semua anggota populasi digunakan sebagai sampel (Setiadi, 2007) sedangkan sampel pada kelompok kontrol adalah suami yang bermukim di sekitar rumah akseptor pengguna vasektomi dengan pencocokan (matching) umur dan jumlah anak sebanyak 30 orang.

Jenis data yang dikumpulkan dalam penelitian ini adalah data primer penelitian diperoleh melalui wawancara kepada responden dengan berpedoman pada kuesioner yang telah disusun dan mengacu pada variabel yang akan diteliti dan data sekunder yang diperoleh dari Dinas Pengendalian Penduduk dan Keluarga Berencana Kabupaten Dairi, BKKBN provinsi Sumatera Utara, Puskesmas, data demografi dan geografi wilayah penelitian dan studi kepustakaan (literatur), dan jurnal kesehatan yang berhubungan dengan penelitian ini.

Analisis data yang dilakukan adalah analisis univariat menjelaskan distribusi frekuensi dari masing-masing variabel independen dan variabel dependen, analisis bivariat untuk mengetahui hubungan antara dua variabel, yaitu variabel dependen dengan variabel independen dengan menggunakan uji chi square dengan derajat kepercayaan $95 \%$, dan analisis multivariat. untuk melihat seberapa besar hubungan variabel independen (pengetahuan, sikap, ketersediaan layanan vasektomi, keterjangkauan sarana kesehatan) secara serentak terhadap variabel dependen (pria pengguna vasektomi dan pria tidak pengguna vasektomi) sehingga diketahui variabel independen yang dominan pengaruhnya terhadap variabel dependen dengan menggunakan regresi logistic ganda (Multiple Logistic Regression).

\section{HASIL DAN PEMBAHASAN}

Kecamatan Sidikalang terdiri dari 6 desa dan 5 kelurahan dengan jumlah Pasangan Usia Subur (PUS) sebanyak 6.553 pasangan.

\section{Analisis Univariat}

\section{Faktor Presdiposisi}

Pengetahuan tentang Vasektomi

Distribusi pengetahuan responden dapat dilihat pada tabel di bawah ini.

Tabel 1. Distribusi Pengetahuan Responden Tentang Vasektomi

\begin{tabular}{clcccc}
\hline \multirow{2}{*}{ No } & \multirow{2}{*}{ Pengetahuan } & \multicolumn{2}{c}{ Kasus } & \multicolumn{2}{c}{ Kontrol } \\
\cline { 3 - 6 } & & $\mathbf{N}$ & $\mathbf{\%}$ & $\mathbf{n}$ & $\mathbf{\%}$ \\
\hline 1 & Baik & 28 & 93,3 & 5 & 16,7 \\
\hline 2 & Kurang & 2 & 6,7 & 25 & 83,3 \\
\hline & Jumlah & $\mathbf{3 0}$ & $\mathbf{1 0 0 , 0}$ & $\mathbf{3 0}$ & $\mathbf{1 0 0 , 0}$ \\
\hline
\end{tabular}

Berdasarkan tabel di atas dapat diketahui bahwa sebagian besar responden pada kelompok kasus berpengetahuan baik dengan jumlah 28 orang (93,3\%), sedangkan responden pada kelompok kontrol berpengetahuan kurang dengan jumlah 25 orang $(83,3 \%)$.

Sikap terhadap Vasektomi

Distribusi sikap responden dapat dilihat pada tabel di bawah ini.

Tabel 2. Distribusi Sikap Responden Tentang Vasektomi

\begin{tabular}{cccccc}
\hline \multirow{2}{*}{ No } & \multirow{2}{*}{ Sikap } & \multicolumn{2}{c}{ Kasus } & \multicolumn{2}{c}{ Kontrol } \\
\cline { 3 - 6 } & & n & \% & n & \% \\
\hline 1 & Baik & 26 & 86,7 & 6 & 20,0 \\
\hline 2 & Kurang & 4 & 13,3 & 24 & 80,0 \\
\hline & Jumlah & $\mathbf{3 0}$ & $\mathbf{1 0 0 , 0}$ & $\mathbf{3 0}$ & $\mathbf{1 0 0 , 0}$ \\
\hline
\end{tabular}

Berdasarkan tabel di atas dapat diketahui bahwa sebagian besar responden pada kelompok kasus bersikap baik dengan jumlah 26 orang $(86,7 \%)$, sedangkan responden pada kelompok kontrol bersikap kurang dengan jumlah 24 orang $(80,0 \%)$

\section{Faktor Pemungkin}

Ketersediaan Pelayanan Vasektomi

Distribusi ketersediaan pelayanan vasektomi menurut responden dapat dilihat pada tabel di bawah ini

Tabel 3. Distribusi Ketersediaan Pelayanan Vasektomi

\begin{tabular}{|c|c|c|c|c|}
\hline \multirow{2}{*}{ No Pelayanan } & \multicolumn{2}{|c|}{ Kasus } & \multicolumn{2}{|c|}{ Kontrol } \\
\hline & n & $\%$ & $\mathbf{N}$ & $\%$ \\
\hline 1 Baik & 28 & 93,3 & 9 & 30,0 \\
\hline 2 Kurang & 2 & 6,7 & 21 & 70,0 \\
\hline jumlah & 30 & 100,0 & 30 & 100,0 \\
\hline $\begin{array}{l}\text { Berdasar } \\
\text { tahui bah } \\
\text { kelompc }\end{array}$ & & tabel & di & atas \\
\hline
\end{tabular}


pelayanan vasektomi tersedia dengan baik dengan jumlah 28 orang $(93,3 \%)$, sedangkan responden pada kelompok kontrol menyatakan bahwa pelayanan vasektomi kurang tersedia dengan jumlah 21 orang $(70,0 \%)$.

Keterjangkauan Sarana Kesehatan

Distribusi keterjangkauan sarana kesehatan menurut responden dapat dilihat pada tabel di bawah ini.

Tabel 4. Distribusi Keterjangkauan Sarana Kesehatan

\begin{tabular}{cccccc}
\hline \multirow{2}{*}{ No } & \multirow{2}{*}{ Sarana } & \multicolumn{2}{c}{ Kasus } & \multicolumn{2}{c}{ Kontrol } \\
\cline { 3 - 6 } & $\mathbf{n}$ & $\mathbf{\%}$ & $\mathbf{n}$ & $\mathbf{\%}$ \\
\hline 1 & Terjangkau & 23 & 76,7 & 12 & 40,0 \\
\hline \multirow{2}{*}{2} & $\begin{array}{l}\text { Kurang } \\
\text { terjangkau }\end{array}$ & 7 & 23,3 & 18 & 60,0 \\
\hline & Jumlah & $\mathbf{3 0}$ & $\mathbf{1 0 0 , 0}$ & $\mathbf{3 0}$ & $\mathbf{1 0 0 , 0}$ \\
\hline \multicolumn{2}{c}{ Berdasarkan } & \multicolumn{2}{c}{ tabel } & di & \multicolumn{2}{c}{ atas } & dapat
\end{tabular}

diketahui bahwa sebagian besar responden pada kelompok kasus menyatakan bahwa keterjangkauan sarana kesehatan dengan kategori terjangkau dengan jumlah 23 orang $(76,7 \%)$, sedangkan responden pada kelompok kontrol menyatakan bahwa keterjangkauan sarana kesehatan dengan kategori kurang dengan jumlah 18 orang $(60,0 \%)$.

\section{Faktor Penguat}

Tabel 6. Tabulasi Silang Pengetahuan Responden dengan Partisipasi Pria dalam Vasektomi

\begin{tabular}{|c|c|c|c|c|c|c|c|c|c|}
\hline \multirow{2}{*}{ No } & \multirow{2}{*}{ Pengetahuan } & \multicolumn{2}{|c|}{ Kasus } & \multicolumn{2}{|c|}{ Kontrol } & \multicolumn{2}{|c|}{ Jumlah } & \multirow{2}{*}{$\underset{(\text { Value })}{\mathbf{p}}$} & \multirow{2}{*}{ OR } \\
\hline & & n & $\%$ & $\mathbf{n}$ & $\%$ & $\mathbf{n}$ & $\%$ & & \\
\hline 1 & Baik & 28 & 46,7 & 5 & 8,3 & 33 & 55,0 & & \\
\hline 2 & Kurang & 2 & 3,3 & 25 & 41,7 & 27 & 45,0 & & $70,00(12,46-397,36)$ \\
\hline & Jumlah & 30 & 50,0 & 30 & 50,0 & 56 & 100,0 & & \\
\hline
\end{tabular}

Dari hasil analisis chi-square antara dalam menentukan pengambilan keputusan pengetahuan responden dengan partisipasi pria dalam vasektomi diperoleh nilai $\mathrm{p}=$ 0,000 dan Odd Ratio (OR) = 70,00 (95\% CI $12,46-393,36)$. Karena nilai p $(0,000)<\alpha$ $(0,05)$, maka dapat disimpulkan bahwa ada hubungan yang signifikan antara pengetahuan responden dengan partisipasi pria dalam vasektomi dan responden yang memiliki pengetahuan baik mempunyai kemungkinan 70 kali lebih besar menjadi akseptor vasektomi. Hasil penelitian tersebut sama dengan penelitian Purwoko (2000) pengetahuan menyumbangkan peran
Dukungan Istri

Distribusi dukungan istri menurut responden dapat dilihat pada tabel dibawah ini:

Tabel 5. Distribusi Dukungan Istri

Berdasarkan tabel di atas dapat diketahui bahwa sebagian besar responden pada kelompok kasus menyatakan bahwa dukungan istri dengan kategori baik dengan jumlah 28 orang $(93,3 \%)$, sedangkan responden pada kelompok kontrol menyatakan bahwa dukungan istri dengan ketegori kurang dengan jumlah 22 orang $(73,3 \%)$.

\section{Analisis Bivariat}

1. Hubungan Pengetahuan dengan Partisipasi Pria dalam Vasektomi

Berdasarkan hasil penelitian yang dilakukan, maka dapat dilihat hubungan antara pengetahuan dengan partisipasi pria dalam vasektomi seperti pada tabel di bawah ini :

\begin{tabular}{|c|c|c|c|c|c|}
\hline \multirow{2}{*}{ No } & \multirow{2}{*}{ Dukungan } & \multicolumn{2}{|c|}{ Kasus } & \multicolumn{2}{|c|}{ Kontrol } \\
\hline & & $\mathbf{n}$ & $\%$ & $\mathbf{n}$ & $\%$ \\
\hline 1 & Baik & 28 & 93,3 & 8 & 26,7 \\
\hline 2 & Kurang & 2 & 6,7 & 22 & 73,3 \\
\hline & Jumlah & 30 & 100,0 & 30 & 100,0 \\
\hline
\end{tabular}

Tabel 7. Tabulasi Silang Sikap Responden dengan Partisipasi Pria dalam Vasektomi

\begin{tabular}{|c|c|c|c|c|c|c|c|c|c|}
\hline \multirow{2}{*}{ No } & \multirow{2}{*}{ Sikap } & \multicolumn{2}{|c|}{ Kasus } & \multicolumn{2}{|c|}{ Kontrol } & \multicolumn{2}{|c|}{ Jumlah } & \multirow{2}{*}{$\underset{(\text { Value })}{\mathbf{p}}$} & \multirow{2}{*}{ OR } \\
\hline & & $\mathbf{n}$ & $\%$ & $\mathbf{n}$ & $\%$ & $\mathbf{N}$ & $\%$ & & \\
\hline 1 & Baik & 26 & 43,3 & 6 & 10,0 & 32 & 53,3 & \multirow{3}{*}{0,000} & \multirow{3}{*}{$26,00(6,53-103,50)$} \\
\hline 2 & Kurang & 4 & 6,7 & 24 & 40,0 & 28 & 46,7 & & \\
\hline & umlah & 30 & $\mathbf{5 0 , 0}$ & 30 & 50,0 & 56 & 100,0 & & \\
\hline
\end{tabular}


Dari hasil analisis chi-square antara sikap responden dengan partisipasi pria dalam vasektomi diperoleh nilai $\mathrm{p}=0,000$ dan Odd Ratio $(\mathrm{OR})=26,00$ (95\% CI 6,53 $-103,50)$. Karena nilai $p(0,000)<\alpha(0,05)$, maka dapat disimpulkan bahwa ada hubungan antara sikap dengan partisipasi pria dalam vasektomi yaitu semakin baik sikap maka semakin baik partisiasi pria dalam vasektomi di Kecamatan Sidikalang Kabupaten Dairi dan suami yang memiliki sikap baik mempunyai kemungkinan 26 kali lebih besar berpartisipasi dalam vasektomi. Hal ini sesuai dengan pendapat yang dikemukakan oleh Saptono (2008) bahwa kurangnya sikap kepedulian terhadap masalah kesehatan reproduksi karena selama ini adanya kebiasaan masyarakat yang menganggap bahwa masalah KB adalah urusan kaum perempuan dan pria tidak pernah terlibat.

\section{Hubungan Ketersediaan Pelayanan Vasektomi dengan Partisipasi Pria dalam Vasektomi}

Berdasarkan hasil penelitian yang dilakukan, maka dapat dilihat hubungan antara ketersediaan pelayanan vasektomi dengan partisipasi pria dalam vasektomi seperti pada tabel di bawah ini :

Tabel 8. Tabulasi Silang Ketersediaan Pelayanan Vasektomi dengan Partisipasi Pria dalam Vasektomi

\begin{tabular}{|c|c|c|c|c|c|c|c|c|c|}
\hline \multirow{2}{*}{ No } & \multirow{2}{*}{ Pelayanan } & \multicolumn{2}{|c|}{ Kasus } & \multicolumn{2}{|c|}{ Kontrol } & \multicolumn{2}{|c|}{ Jumlah } & \multirow{2}{*}{$\begin{array}{c}\mathbf{p} \\
(\text { Value })\end{array}$} & \multirow{2}{*}{ OR } \\
\hline & & $\mathbf{n}$ & $\%$ & n & $\%$ & n & $\%$ & & \\
\hline 1 & Baik & 28 & 46,7 & 9 & 15,0 & 37 & 61,7 & \multirow{3}{*}{0,000} & \multirow{3}{*}{$32,67(6,38-167,28)$} \\
\hline 2 & Kurang & 2 & 3,3 & 21 & 35,0 & 23 & 38,3 & & \\
\hline & Jumlah & 30 & $\mathbf{5 0 , 0}$ & 30 & 50,0 & 56 & 100,0 & & \\
\hline
\end{tabular}

Dari hasil analisis chi-square antara ketersediaan pelayanan vasektomi menurut responden dengan partisipasi pria dalam vasektomi diperoleh nilai $\mathrm{p}=0,000$ dan Odd Ratio $(\mathrm{OR})=32,67(95 \%$ CI 6,38$167,28)$. Karena nilai $\mathrm{p}(0,000)<\alpha(0,05)$, maka dapat disimpulkan bahwa ada hubungan antara ketersedian pelayanan vasektomi dengan partisipasi pria dalam vasektomi yaitu semakin baik ketersediaan pelayanan kesehatan maka semakin baik partisiasi pria dalam vasektomi di Kecamatan Sidikalang Kabupaten Dairi dan suami yang menyatakan ketersediaan pelayanan vasektomi baik mempunyai kemungkinan 32,67 kali lebih besar berpartisipasi dalam vasektomi. Menurut

Kartono dalam Hutauruk (2006), PUS tidak memanfaatkan pelayanan KB karena penyedia pelayanan KB tidak menyediakan semua metode kontrasepsi. Petugas cenderung memprioritaskan salah satu alat kontrasepsi sehingga membatasi suatu metode kontrasepsi tertentu karena keterbatasan persediaan.

\section{Hubungan Keterjangkauan Sarana Kesehatan dengan Partisipasi Pria dalam Vasektomi}

Berdasarkan hasil penelitian yang dilakukan, maka dapat dilihat hubungan antara keterjangkauan sarana kesehatan dengan partisipasi pria dalam vasektomi seperti pada tabel di bawah ini :

Tabel 9.Tabulasi Silang Keterjangkauan Sarana Kesehatan dengan Partisipasi Pria dalam Vasektomi

\begin{tabular}{|c|c|c|c|c|c|c|c|c|c|}
\hline \multirow{2}{*}{ No } & \multirow{2}{*}{$\begin{array}{l}\text { Pelayanan } \\
\text { Kesehatan }\end{array}$} & \multicolumn{2}{|c|}{ Kasus } & \multicolumn{2}{|c|}{ Kontrol } & \multicolumn{2}{|c|}{ Jumlah } & \multirow{2}{*}{$\underset{(\text { Value })}{\mathbf{p}}$} & \multirow{2}{*}{ OR } \\
\hline & & n & $\%$ & $\mathbf{n}$ & $\%$ & n & $\%$ & & \\
\hline 1 & Terjangkau & 23 & 38,3 & 12 & 20,0 & 35 & 58,3 & \multirow{3}{*}{0,008} & \multirow{3}{*}{$4,93(1,61-15,07)$} \\
\hline 2 & Kurang terjangkau & 7 & 11,7 & 18 & 30,0 & 25 & 41,7 & & \\
\hline & Jumlah & 30 & 50,0 & 30 & $\mathbf{5 0 , 0}$ & 56 & 100,0 & & \\
\hline
\end{tabular}

Dari hasil analisis chi-square antara keterjangkauan sarana kesehatan menurut responden dengan partisipasi pria dalam vasektomi diperoleh nilai $\mathrm{p}=0,008$ dan Odd Ratio $(\mathrm{OR})=4,93(95 \%$ CI $1,61-$ $15,07)$. Karena nilai $\mathrm{p}(0,008)<\alpha(0,05)$, maka dapat disimpulkan bahwa ada hubungan antara keterjangkauan sarana 
kesehatan dengan partisipasi pria dalam vasektomi yaitu semakin baik keterjangkauan fasilitas kesehatan maka semakin baik partisiasi pria dalam vasektomi di Kecamatan Sidikalang Kabupaten Dairi dan suami yang menyatakan keterjangkauan fasilitas kesehatan baik mempunyai kemungkinan 4,93 kali lebih besar berpartisipasi dalam vasektomi. Jarak dengan fasilitas kesehatan juga berkontribusi terhadap terciptanya suatu perilaku kesehatan pada masyarakat. Sarana pendukung pelayanan Keluarga Berencana (KB) di Kecamatan Sidikalang terdiri dari 4 klinik KB, tetapi hanya RSUD Sidikalang yang melayani pelayanan vasektomi. Hal ini cukup memberatkan bagi

Tabel 10. Tabulasi Silang Dukungan Istri dengan Partisipasi Pria dalam Vasektomi

\begin{tabular}{|c|c|c|c|c|c|c|c|c|c|}
\hline \multirow{2}{*}{ No } & \multirow{2}{*}{ Dukungan } & \multicolumn{2}{|c|}{ Kasus } & \multicolumn{2}{|c|}{ Kontrol } & \multicolumn{2}{|c|}{ Jumlah } & \multirow{2}{*}{$\underset{(\text { Value })}{\mathbf{p}}$} & \multirow{2}{*}{ OR } \\
\hline & & $\mathbf{n}$ & $\%$ & & $\%$ & $\mathbf{n}$ & $\%$ & & \\
\hline 1 & Baik & 28 & 46,7 & 8 & 13,3 & 36 & 60,0 & \multirow{3}{*}{0,000} & \multirow{3}{*}{$38,50(7,42-199,87)$} \\
\hline 2 & Kurang & 2 & 3,3 & 22 & 36,7 & 24 & 40,0 & & \\
\hline & Jumlah & 30 & 50,0 & 30 & 50,0 & 56 & 100,0 & & \\
\hline
\end{tabular}

Dari hasil analisis chi-square antara dukungan istri menurut responden dengan partisipasi pria dalam vasektomi diperoleh nilai $\mathrm{p}=0,000$ dan Odd Ratio $(\mathrm{OR})=38,50$ (95\% CI 7,42 - 199,87). Karena nilai $\mathrm{p}$ $(0,000)<\alpha(0,05)$, maka dapat disimpulkan bahwa ada hubungan antara dukungan istri dengan partisipasi pria dalam vasektomi yaitu semakin baik dukungan istri maka semakin baik partisipasi pria dalam vasektomi di Kecamatan Sidikalang Kabupaten Dairi dan suami yang menyatakan dukungan istri baik mempunyai kemungkinan 38,50 kali lebih besar berpartisipasi dalam vasektomi. Adanya dukungan dari keluarga khususnya istri akan memengaruhi suami untuk berpartisipasi dalam vasektomi. Adanya sebagian masyarakat yang bertempat tinggal jauh dan tidak memperoleh akses transportasi umum.

\section{Hubungan Dukungan Istri dengan Partisipasi Pria dalam Vasektomi}

Berdasarkan hasil penelitian yang dilakukan, maka dapat dilihat hubungan antara dukungan istri dengan partisipasi pria dalam vasektomi seperti pada tabel di bawah ini :

Tabel 11. Hasil Seleksi Bivariat antara Variabel Pengetahuan, Sikap, Ketersediaan Pelayanan Vasektomi, Keterjangkauan Sarana Kesehatan dan Dukungan Istri Terhadap Partisipasi Pria dalam Vasektomi

\begin{tabular}{clcc}
\hline No & \multicolumn{1}{c}{ Variabel } & p Value & \multicolumn{1}{c}{ Keterangan } \\
\hline 1 & Pengetahuan & 0,000 & $<0,25$ sehingga dimasukkan dalam analisis multivariat \\
\hline 2 & Sikap & 0,000 & $<0,25$ sehingga dimasukkan dalam analisis multivariat \\
\hline 3 & $\begin{array}{l}\text { Ketersediaan Pelayanan } \\
\text { Vasektomi }\end{array}$ & 0,000 & $<0,25$ sehingga dimasukkan dalam analisis multivariat \\
\hline 4 & $\begin{array}{l}\text { Keterjangkauan Sarana } \\
\text { Kesehatan }\end{array}$ & 0,008 & $<0,25$ sehingga dimasukkan dalam analisis multivariat \\
\hline 5 & Dukungan Istri & 0,000 & $<0,25$ sehingga dimasukkan dalam analisis multivariat \\
\hline
\end{tabular}

Hasil analisis multivariat dengan menggunakan regresi logistik ganda diperoleh hasil seperti yang disajikan dalam table berikut ini : 
Tabel 12. Hasil Analisis Multivariat Tahap Pertama antara Variabel Pengetahuan, Sikap, Ketersediaan Pelayanan Vasektomi, Keterjangkauan Sarana Kesehatan dan Dukungan Istri

Terhadap Partisipasi Pria dalam Vasektomi

\begin{tabular}{lcccc}
\hline \multicolumn{1}{c}{ Variabel } & B & p value & Exp B & 95\% CI \\
\hline Pengetahuan & 22,186 & 0,998 & 4,318 & $0,000-0,000$ \\
\hline Sikap & 0,915 & 0,572 & 2,498 & $0,105-59,650$ \\
\hline Ketersediaan Pelayanan Vasektomi & 1,880 & 0,352 & 6,5552 & $0,125-343,172$ \\
\hline Keterjangkauan Sarana Kesehatan & $-18,663$ & 0,999 & 0,000 & $0,000-0,000$ \\
\hline Dukungan Istri & 1,865 & 0,166 & 6,457 & $0,462-90,181$ \\
\hline Konstanta & -11.014 & & &
\end{tabular}

Selanjutnya dilakukan analisis tahap kedua seperti pada tabel di bawah ini :

Tabel 13. Hasil Analisis Multivariat Tahap Terakhir antara Variabel Pengetahuan, Ketersediaan Pelayanan Vasektomi, dan Dukungan Istri Terhadap Partisipasi Pria dalam Vasektomi

\begin{tabular}{lcccc}
\hline \multicolumn{1}{c}{ Variabel } & B & p value & Exp B & 95\% CI \\
\hline Pengetahuan & 3,932 & 0,000 & 51,016 & $5,796-449,055$ \\
\hline Ketersediaan Pelayanan Vasektomi & 2,291 & 0,066 & 9,882 & $0,857-113,938$ \\
\hline Dukungan Istri & 2,363 & 0,053 & 10,622 & $0,967-116,686$ \\
\hline Konstanta & $-11,628$ & & & \\
\hline & & & &
\end{tabular}

Berdasarkan nilai beta (B) yang Adapun beberapa hal yang disarankan tertinggi adalah variabel pengetahuan yaitu 3,932. Ini menunjukkan bahwa variabel tersebut merupakan variabel yang paling dominan memengaruhi partisipasi pria dalam vasektomi. Besar pengaruh variabel tersebut dapat dilihat/dari nilai $\operatorname{Exp}$ (B), yaitu 51,043, artinya variabel pengetahuan mempunyai pengaruh 51 kali terhadap partisipasi pria dalam vasektomi pada responden. Hal ini dapat diartikan bahwa suami yang mempunyai pengetahuan baik mempunyai peluang 51 kali untuk berpartisipasi dalam vasektomi dibandingkan dengan suami yang tidak memiliki pengetahuan yang baik.

\section{KESIMPULAN}

Berdasarkan penelitian yang telah dilakukan dapat disimpulkan faktor presdiposisi (pengetahuan dan sikap) berpengaruh terhadap partisipasi pria dalam vasektomi di Kecamatan Sidikalang Kabupaten Dairi, faktor pemungkin (keterjangkauan fasilitas kesehatan dan ketersediaan pelayanan vasektomi) berpengaruh terhadap partisipasi pria dalam vasektomi di Kecamatan Sidikalang Kabupaten Dairi, faktor penguat (dukungan istri) berpengaruh terhadap partisipasi pria dalam vasektomi di Kecamatan Sidikalang Kabupaten Dairi, dan faktor yang paling dominan terhadap partisipasi pria dalam vasektomi yaitu pengetahuan.

SARAN yaitu bagi keluarga khususnya istri diharapkan mendukung suami sehingga mau berpatisipasi dalam vasektomi dan juga aktif mencari informasi yang berhubungan dengan vasektomi, bagi pria PUS dapat berpatisipasi terhadap KB khususnya vasektomi dengan cara mengikuti penyuluhan dan mencari informasi mengenai vasektomi baik dari petugas kesehatan maupun Penyuluh Lapangan Keluarga Berencana (PLKB), bagi PLKB agar memberikan informasi yang jelas kepada masyarakat baik melalui penyuluhan dan konseling. Perlu ditingkatkan kerjasama antara BKKBN, Dinas Pengendalian Penduduk dan Keluarga Berencana Kabupaten Dairi dan Puskesmas untuk membuat suatu program lintas sektoral dalam meningkatkan jumlah akseptor KB, seperti pelaksanaan pelayanan vasektomi rutin paling tidak $2 \mathrm{x}$ setahun. Bagi Dinas Pengendalian Penduduk dan Keluarga Berencana agar melakukan kegiatan kaderisasi kepada akseptor vasektomi agar mereka dapat menjadi kader vasektomi sehingga meningkatkan kesediaan suami dalam menggunakan vasektomi. Tenaga petugas PLKB perlu ditambah sehingga dapat menjangkau seluruh masyarakat di Kecamatan Sidikalang Kabupaten Dairi, dan Bagi Pemerintah Kabupaten Dairi agar meningkatkan keterjangkauan sarana kesehatan dengan menambah jumlah dan rute transportasi umum dan perbaikan infrastruktur jalan. 


\section{DAFTAR PUSTAKA}

Abdullah, Irwan. (2003). Sangkan Paran Gender, Yogyakarta: Pustaka Pelajar.

Ancok Djamaludin. (2002). Teknik Penyusunan Skala Pengukur, Pusat Study Kependudukan dan Kebijakan. Yogyakarta: UGM.

Anonim. Visi dan Misi BKKBN, www.bkkbn.go.id, tanggal 23 Maret 2017.

Azwar, Saefudin. (1988). Sikap Manusia Teori dan Pengukurannya. Yogyakarta: Liberty.

Azwar, S. (2001). Pengantar Pendidikan Kesehatan. Jakarta: sastra Hudaya.

BKKBN. (2000). Peningkatan Peran Suami Dalam Pelaksanaan KB di Lingkungan Keluarganya. Jakarta: BKKBN.

BKKBN. (2002). Panduan Pelayanan Keluarga Berencana dan Kesehatan Reproduksi Berwawasan Gender. Jakarta: BKKBN.

BKKBN. (2003). Bunga Rampai: Bahan Pembelajaran

Pelatihan Pengarusutamaan Gender Dalam Program Pembangunan Nasional. Jakarta: BKKBN.

BKKBN. (2004). Panduan Pelayanan KB dan Kesehatan Reproduksi Berwawasan Gender di Tempat Kerja. Jakarta: BKKBN.

BKKBN. (2004) Peningkatan Partisipasi Pria Dalam Keluarga Berencana dan Kesehatan Reproduksi. Jakarta: BKKBN.

BKKBN. (2006). Gema Partisipasi Pria, No. 5/V/2006. Jakarta: BKKBN.

BKKBN. (2012). Peningkatan Partisipasi Pria Dalam Keluarga Berencana dan Kesehatan Reproduksi. Jakarta: BKKBN.

BKKBN. (2015). Rencana Pembangunan Jangka Menengah Badan Kependudukan, Keluarga Berencana dan Pembangunan Kependudukan. Jakarta: BKKBN.

BKKBN. (2016). Operasionalisasi Program dan Kegiatan Strategis Peningkatan Partisipasi Pria dalam Keluarga Berencana dan Kesehatan Reproduksi. Jakarta: BKKBN.

BKKBN. (2017). Laporan Bulanan Program KB Kabupaten Dairi. Dairi: BKKBN.
BPS. (2013). Proyeksi Penduduk Indonesia 2010-2035. Jakarta: BPS.

Budisantoso, S. I. (2009). Partisipasi Pria dalam Keluarga Berencana di Kecamatan Jetis Kabupaten Bantul. Jurnal Promosi Kesehatan Indonesia vol. 4.

Depkes RI. (1990). Buku Pedoman Petugas Klinik Keluarga Berencana. Jakarta: Depkes RI.

Ellya, Eva. Dkk. (2010). Kesehatan Reproduksi Wanita. Jakarta: Trans Info Media.

Ernawati. (2016). Faktor yang Memengaruhi Keluarga Berencana (KB) Pria dengan Patisipasi Pria Dalam Keluarga Berencana di Wilayah Kerja Puskesmas Sedayu II. Jurnal Ners dan Kebidanan Indonesia. http://ejournal.almaata.ac.iid/index.php $/ \mathrm{JNKI}$

Gasperzs, Vincent. (1997). Teknik Penarikan Contoh untuk Penelitian Survey. Bandung: Tarsito.

Green, Lawrence W. Health Promotion Planning An Educational and Environmental Approac.,

Hanafiah, J. (1986). Aspek Sosial Budaya dan Agama Kontap. Jakarta: PKMI.

Hastono, Sutanto Priyo. (2006). Basic Data Analysis for Health Research. Jakarta: Universitas Indonesia.

Hutauruk, A. (2006). Hubungan Karakteristik Wanita Usia Subur (WUS) dan Kualitas Pelayanan KB dengan Utilisasi Pelayanan $K B$ di Kabupaten Tapanuli Tengah. Tesis. Medan: Sekolah Pascasarjana Universitas Sumatera Utara.

Iman, S. (2008). Faktor-Faktor Yang Berhubungan Dengan Partisipasi Pria DalamKeluarga Berencana Di Kecamatan Jetis Kabupaten Bnatul Tahun 2008. Tesis. Semarang: Magister Promosi Kesehatan Universitas Diponegoro.

Kartono, K. (1990). Psikologi Umum. Bandung: Mandar Maju.

Maharyani, W. H., Handayani, S. (2010). Hubungan Karakteristik Suami dengan Kikutsertaan Suami Menjadi Akseptor Keluarga Berencana di Wilayah Desa Karang Duwur Kecamatan Petanahan Kabupaten Kebumen Jawa Tengah. Skripsi. Yogyakarta: FKM Universitas Ahmad Dahlan. 
Manuaba, Ida B.G. (1998). Ilmu Kebidanan, Penyakit Kandungan \& Keluarga Berencana untuk Pendidikan Bidan. Jakarta : EGC.

Nazir, M. (2003). Metode Penelitian. Jakarta: Ghalia Indonesia.

Niven, Neil. (2002). Psikologi Kesehatan. Jakarta: EGC.

Notoatmojo, Soekidjo. (1990). Pengantar Perilaku Kesehatan. Jakarta: FKM UI.

Notoatmojo, Soekidjo. (2005). Promosi Kesehatan Teori dan Aplikasi. Jakarta: Rineka Cipta.

Notoatmojo, Soekidjo. (2007). Promosi Kesehatan \& Ilmu Perilaku. Jakarta: Rineka Cipta.

Novianti. (2014). Faktor Persepsi dan Dukungan Isteri Yang Berhubungan Dengan Partisipasi KB Pria. Jurnal Kesehatan KomunitasVol, 10 No, 2, 2014 hal 1017-1027.

Sarwono, Sarlito Wirawan. (2005). Psikologi Remaja. Jakarta: Raja Grafindo Persada.

Saifuddin, dkk. (2003). Buku Panduan Praktis Pelayanan Kontrasepsi. Jakarta: Yayasan Bina Pustaka Sarwono Prawirohardjo.

Putra,Edisa G. (2015). Pengaruh Faktor Personal, Sosial dan Situasional terhadap Keikutsertaan Vasektomi di Kecamatan Sidikalang Kabupaten Dairi. Tesis. Medan: Universitas Sumatera Utara

Putri, D. (2016). Faktor Yang Memepengaruhi Partisipasi Pria Dalam Penggunaan Metode Kontrasepsi Vasektomi di Kecamatan Payangan Kabupaten Gianyar. Skipsi. Bali: Universitas Udayana.

Purwoko. (2000). Penerimaan Vasektomi dan Sterilisasi Tuba. Tesis. Semarang: Fakultas Kedokteran Universitas Diponegoro.
Ratmina. (2011). Faktor-Faktor yang Berhubungan Dengan Penggunaan Kontrasepsi Vasektomi Pada Pria PUS Di Kabupaten Deli Serdang. Tesis. Medan: FKM Universitas Sumatera Utara.

Setiadi. (2007). Konsep \& Penelitian Riset Keperawatan. Yogyakarta: Graha Ilmu.

Soekanto, S. (2007). Sosiologi suatu Pengantar. Jakarta: Raja Grafindo.

Sugiyono. (1999). Statistik Untuk Penelitian. Bandung: Alfabeta.

Supriyadi. (2014). Statistik Kesehatan. Jakarta: Salemba Medika.

Suprihastuti. (2000). Pengambilan Keputusan Penggunaan Alat Kontrasepsi Pria di Indonesia. Analisis Hasil SDKI 1997. Jakarta.

Tatarini, Junita. (2008). Faktor-faktor yang mempengaruhi Pemakaian alat kontrasepsi pada istri PUS di Kecamatan Rambah Samo Kabupaten Rokan Hulu. Medan: Universitas Sumatera Utara.

Usman, Husaini. (2008). Pengantar Statistika. Jakarta: BumiAksara.

Wijayanti. (2004). Studi Kualitatif Alasan Akseptor Laki-Laki tidak Memilih MOP sebagai Kontrasepsi Pilihan di desa Timpik kecamatan Susukan kabupaten Semarang. Semarang: Publikasi Ilmiah Program Studi D IV Kebidanan Stikes Ngudi Waluyo

Wiyatmi. (2014). Faktor-faktor Yang Berhubungan Dengan Sikap Pria Pasangan Usia Subur (PUS) Tentang Metode Kontrasepsi Vasektomi di Desa Winong Kecamatan Boyolali Kabupaten Boyolali. Naskah Publikasi. Surakarta: Universitas Muhammadiyah Surakarta. 